\title{
MATHEMATICAL MODEL STUDY ON SOLVENT EXTRACTION OF CAROTENE FROM CARROT
}

\author{
Sudipta Das ${ }^{1}$, Debabrata Bera ${ }^{2}$ \\ ${ }^{1}$ M.Tech Student, ${ }^{2}$ Assistant Professor, Food Technology, Techno India, West Bengal, India, \\ beradebabrata@yahoo.co.in
}

\begin{abstract}
Carotenoids are known as provitamin A, while there is an increasing interest in their role as an antioxidants. Anti-cancer activity and other health benefits provided by $\beta$-carotene include the protection against cardiovascular disease and cataract prevention, Carrots are one of the best sources of $\beta$-carotene. In this paper we have studied the influence of particle size, temperature, solvents, solid is to solvent ratio and extraction time on the extraction yield of $\beta$-carotene, and verification of different models and rate kinetics to establish the extraction mechanism.
\end{abstract}

Ethanol, pet ether, ethyl acetate \& $n$-hexane are used as solvent and carrot of cubes of equivalent diameter of $1.077 \pm 0.134 \mathrm{~cm}$, $0.801 \pm 0.1078 \mathrm{~cm} \& 0.508 \pm 0456 \mathrm{~cm}$ are used for solvent ratios from 1:5 to 1:60. Temperature was varied from 30 to $50^{0} \mathrm{C}$. Experimental results better fitted in power law model than Peleg model also it obey Pseudo second order kinetic \& Intraparticle diffusion model. Extent of color extraction is established by Hunter Lab colorimeter.

Index terms- carrot, carotene, solvent extraction, kinetic study, model study

$* * *$

\section{INTRODUCTION}

Nutraceuticals and functional food ingredients are known to improve health [1,2]. Carotenoids are well known for their antioxidant activity and therefore have a neuroprotective effect. They are known to have effect against singlet oxygen, inhibit LDL cholesterol oxidation, control the risk of a range of different cancers and improve cognitive development [1]. Carrot is one rich source of carotenoids; the reported values are in the range of $16-38 \mathrm{mg} / 100 \mathrm{~g}[3,4,5]$.

Fresh carrots sold in the market are subjected to strict market polices ,i.e., carrots should meet set standards of size and shape, and as a result of this, some $25 \%$ of the carrots produced never make it to the market. The uncontrollable nature of carrot production results in a quarter of the harvest to be regarded as by-product [6].

The aim of this study was to make beneficial pharmaceutical use of carrot by-product by extracting high-valued carotenoids from them. Established methods for the extraction of carotenoids require the use of different organic solvents in which carrotinoids are soluble [7, 8, 9].

Liquid-liquid extraction of carotenoids using organic solvents has been reviewed by Quiros \& Costa, 2006 [10]. These organic solvents are regarded as costly, environmentally hazardous, and require expensive disposal procedures. There are however several studies pointing at the use of supercritical carbon dioxide as extraction solvent for carotenoids from carrots $[5,10,11]$. Ethanol has a relatively low environmental impact and has a positive net energy balance (NEB) $[12,13]$ and is a generally recognized as safe (GRAS) solvent. Nevertheless, the sustainability of ethanol depends majorly on the source from which it was produced. Most of them are toxic and expensive [14]. So another purpose of this study was to find the appropriate conditions for the extraction of $\beta$-carotene from carrot. The main goals were to study the influence of temperature, samples treatment, and solvents on the extraction yield of $\beta$-carotene, and to utilize the knowledge for the establishment of the technology for obtaining biologically active concentrates of carotenoids made from the rich natural source-carrot, as well as determination of different kinetic parameters to justify the extraction mechanism.

\section{MATERIALS AND METHODS}

\subsection{Material}

\section{Raw Material Preparation}

The carrot sample was collected from local market of Kolkata and was used for laboratory experiments. These were washed with distilled water to removed sands and dust particles from outer surface. Then adherent water was removed by dry cloth. After peeling the carrot samples were cut into small pieces with the help of a sharp knife into cubical shapes with equivalent diameter of $1.077 \pm 0.134 \mathrm{~cm}, 0.801 \pm 0.1078 \mathrm{~cm} \mathrm{\&}$ $0.508 \pm .0456 \mathrm{~cm}$. These slices were used for carotene 
extraction under different environmental conditions, kinetics study and physicochemical parameters of raw material except bulk density in which case raw carrots were used. The solvents used in these study, were obtained from the Merck India Ltd.

\subsection{Methods}

\subsubsection{Determination of Physical Parameters of Carrot}

\section{Sample}

The moisture content of carrot was determined gravimetrically, at $105^{\circ} \mathrm{C}$ for $4.5 \mathrm{hr}$ upto constant weight and Bulk density was measured by sand displacement method. The color quality of carrot, before and after extraction was determined by Hunter Lab colorimeter. (Color flex 45/0 spec photometer). The color of carrot was assessed using a colorimeter with a CIE standard illuminant $\mathrm{C}$ to determine CIE color space co-ordinates, $L^{*} a * b *$ values. Lightness value $\mathrm{L}^{*}$ indicates how dark /light the sample is (varying from 0 black to 100 -white), $a^{*}$ is a measure of greenness/redness, (varying from -60 to +60 ) and $b^{*}$ is the grade of blueness / yellowness (also varying from -60 to +60 ). The polar coordinate chroma or saturation, $\mathrm{c}^{*}$ is an indication of how dull / vivid the product is (ranging from 0-60), which can be calculated from the $\mathrm{L}^{*} \mathrm{a}^{*}$ and $\mathrm{b}^{*}$ cartesian co-ordinate by the expression

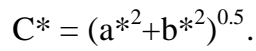

The total color difference (TCD) or $\Delta \mathrm{E}$ [15] was the parameter considered for the overall color difference evaluation between raw carrot and carrot after solvent extraction.

$$
\mathrm{TCD}=\left(\Delta \mathrm{L}^{2}+\Delta \mathrm{a}^{2}+\Delta \mathrm{b}^{2}\right)^{0.5}
$$

The colorimeter was calibrated against standard white reference tiles. Samples were placed in a glass Petri dish and color measurements were done in triplicate. Changes in the individual color parameters of carrot before and after extraction were calculated as

$$
\Delta \mathrm{L}=\left(\mathrm{L}-\mathrm{L}_{0}\right) ; \Delta \mathrm{a}=\left(\mathrm{a}-\mathrm{a}_{0}\right) ; \Delta \mathrm{b}=\left(\mathrm{b}-\mathrm{b}_{0}\right)
$$

Where, $+\mathrm{a}$ is redness, $-\mathrm{a}$ is greenness, $+\mathrm{b}$ is yellowness, and $-\mathrm{b}$ is blueness (Minolta, 1999). $\mathrm{L}_{0}, \mathrm{a}_{0}$ and $\mathrm{b}_{0}$ are the color values for fresh carrots, while $\mathrm{L}, \mathrm{a}$ and $\mathrm{b}$ are the color values in carrot after extraction.

\subsubsection{Extraction Conditions.}

The extraction yield of carotenes was observed at different temperatures $\left(30^{\circ} \mathrm{C}, 40^{\circ} \mathrm{C}\right.$, and $\left.50^{\circ} \mathrm{C}\right)$ using ethanol , 2propanol, pet ether and n-hexane. Initially, $18 \mathrm{gm}$ of carrot slices were added to different solvents at different solid to liquid ratio, (1:5), (1:10), (1:15), (1:20), (1:30), (1:40),(1:50) and $(1: 60)$. Carrot slices were extracted in water bath $\left(30^{\circ} \mathrm{C}\right.$, $40^{\circ} \mathrm{C}, 50^{\circ} \mathrm{C}$ ), shaking every $10 \mathrm{~min}$, and $5 \mathrm{ml}$ sample was taken after a certain time interval for carotene concentration measurement by spectrophotometer.

\subsubsection{Assay Method of Carotenes.}

The $\beta$-carotene content in the organic solvents after extraction was determined spectrophotometrically at the wavelength of $450 \mathrm{~nm}$.The concentration of carotenes expressed as $\beta$ carotene content $(\mathrm{g} / 100 \mathrm{ml})$ was calculated using the response factors as follows [9]:

$$
\beta \text {-carotene }=(\mathrm{A} \times \mathrm{d} \times \mathrm{V}) /\left(\mathrm{E}^{1 \%} 1 \mathrm{~cm} \times \mathrm{w}\right) \ldots
$$

Where:

A - Absorbency

d - Dilution.

$\mathrm{E}^{1 \%}{ }_{1 \mathrm{~cm}}$ - Coefficient of absorbency of organic solvent

$\mathrm{w}$ - Weight of sample (g)

$\mathrm{V}-$ Volume $(\mathrm{ml})$

\subsubsection{Kinetic Models Study}

Power law model is used for the diffusion of an active agent through non-swelling devices and is described by equation:

$$
\mathrm{q}=\mathrm{B} \cdot \mathrm{t}^{\mathrm{n}}
$$

Where B is a constant incorporating the characteristics of the carrier-active agent system and $\mathrm{n}$ is the diffusion exponent. For the extraction from vegetable material, the diffusion exponent is less than $1(n<1)[16]$.

The hyperbolic model is known also as Peleg model, 1988 [17] was proposed for the description of moisture sorption curves. The mathematical expression of this model is given by equation:

$$
\mathrm{q}=\mathrm{K}_{1} \mathrm{t} /\left(1+\mathrm{K}_{2} \mathrm{t}\right)
$$

Where $K_{1}$ and $K_{2}$ are parameters of the hyperbolic model The equation 5 was used to model the experimental data obtained for resinoid extraction from aerial parts of St. John'swort and for total polyphenols extraction from soybeans [18, 19].

Weibull's equation can be also applied for plant extraction in the following form:

$$
q=1-\exp (-(
$$

Where $\delta$ is the scale parameter, which is related to the reciprocal of the extraction rate constant and $m$ is the shape parameter. If $m<1$, as in the case of extraction, the curve is parabolic with a high initial slope followed by an exponential shape [16]. 
The pseudo second-order equation is also based on the desorption capacity of the solid phase [20]. The integrated form of the equation is

$$
1 /(\mathrm{qe}-\mathrm{qt})=1 / \mathrm{qe}+\mathrm{k} 2 \mathrm{t}
$$

Here, $k_{2}$ is the second-order rate constant. The linear form of the Equation is

$$
\mathrm{t} / \mathrm{qt}=1 / \mathrm{h}+(1 / \mathrm{qe}) \mathrm{t}
$$

Where $\mathrm{h}=\mathrm{k} 2$.qe 2 can be regarded as the initial sorption rate. If the pseudo second-order kinetics is applicable, the plot of $\mathrm{t} / \mathrm{qt}$ versus $\mathrm{t}$ gives a linear relationship, which allows computation of qe, $\mathrm{k}_{2}$ values.

The Intraparticle diffusion model was considered in order to determine the participation of this process in the desorption of carotene from carrot. According to this model, the plot of desorped amount $(\mathrm{q} t)$, versus the square root of time $\left(\mathrm{t}^{0.5}\right)$ should be linear if intraparticle diffusion is involved in the overall desorption mechanism. Further-more, if this line passes through the origin then the intra particle diffusion is the rate-controlling step of the process. The initial rate of intra particle diffusion, $\mathrm{K}_{\mathrm{d}}$, can be calculated in the following way (Slovak Technical standard 1986) [21].

$$
\mathrm{q}_{\mathrm{t}}=\mathrm{K}_{\mathrm{d}} \mathrm{t}^{0.5}
$$

Where qt is the amount of carotene on the surface of the carrot at time $\mathrm{t}\left(\mathrm{mgg}^{-1}\right), \mathrm{K}_{\mathrm{d}}$ is the intra-particle rate constant $\left(\mathrm{mg}(\operatorname{gmin} 0.5)^{-1}\right)$ and $\mathrm{t}$ is the time (min).

\section{RESULTS AND DISCUSSIONS}

\subsection{Effect of Particle Size and Solvent}

Four different solvents were used to evaluate their extraction efficiency. All these solvents were used for three different particle sizes of equivalent diameter $1.077 \pm 0.134 \mathrm{~cm}$, $0.801 \pm 0.1078 \mathrm{~cm} \quad \& \quad 0.508 \pm .0456 \mathrm{~cm}$. The $\beta$-carotene extraction capacity of $n$-hexane, ethyl acetate and petroleum ether and ethanol is presented in Table: 1 .

Where we can see that the highest extraction yield is obtained when ethanol is used as solvent and when particle size is $0.508 \pm 0.0456 \mathrm{~cm}$. So, farther experiments were carried out using particle size with equivalent diameter $0.508 \pm 0.0456 \mathrm{~cm}$ and ethanol as solvent.

Extraction of beta-carotene is a mass transfer phenomenon from carrot to organic solvent. Mass transfer rate and amount of extraction depends on the surface area. Particles of same mass with smaller particle size have higher surface area. So, carrot pieces with smaller equivalent diameter are more efficient for beta-carotene extraction.
In general, carotenoids are hydrophobic molecules and thus are soluble only in organic solvents, having only limited solubility in water. Presence of hydroxyl groups at the end groups causes the carotenoid to become more polar, affecting its solubility in various organic solvents. Raw carrot contains about $87 \%$ moisture. $\mathrm{N}$-hexane is most non polar among four solvents used in this experiment. Due to antagonistic nature with water it is not properly distributed into the carrot cubes. So extraction efficiency of $n$-hexane is minimum. On the other hand ethanol is polar and it is properly distributed inside the carrot cubes. Beta carotene thus extracted more in ethanol form the inner matrix of carrot.

Carotenoids are soluble in polar solvents, including edible fats and oils. Because carotenoids are liposoluble, they are usually extracted from the plant sources with organic solvents [22]. The samples can contain large amounts of water; watermiscible organic solvents such as ethanol are also used. One of the problems is the elimination of the residual solvents to obtain a safe extract; this can be avoided by using food grade solvents such as ethanol. Calvo et al., 2007 found that the yield of each $(\alpha \& \beta)$ carotene from peel powder of tomatoes was noticeably higher with extraction performed with ethanol than with that using ethyl acetate [23].

\subsection{Effect of Solid / Solvent Ratio}

For this experiment solid-solvent ratio was varied from 1:5 to $1: 60$ at $30^{\circ} \mathrm{C}$. Figure 1 shows that, the amount of $\beta$-carotene extracted increases with solid to solvent ratio up to 1:40 and then it varies little. So, next experiments were carried out using solid-solvent ratio of 1:40.Extraction rate and amount of extraction depend on concentration gradient between carrot particles and organic solvents. Concentration gradients of carotene increased with increase in solid-solvent ratio and hence extraction amount increased up to 1:40.

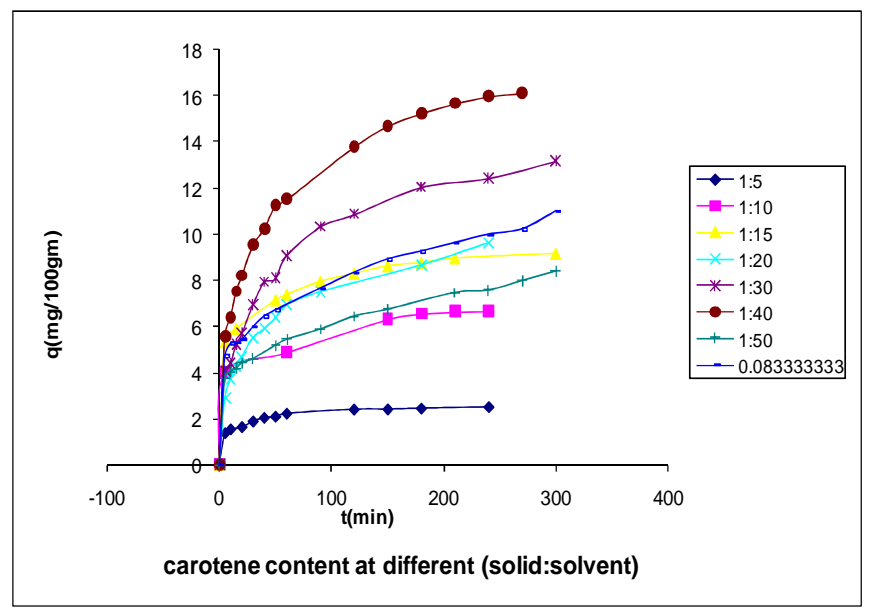

Fig- 1: Amount of beta-carotene extracted from carrot in ethanol at different solid/liquid ratios $\left(30^{\circ} \mathrm{C}\right)$ 
From figure: 1 we can conclude that when the solid to solvent ratio is increased, the amount of carotene extracted increases also\& the highest extraction yield is obtained when solid and solvent ratio is (1:40).

\subsection{Effect of Temperature}

The effect of temperature on the $\beta$-carotene extraction is presented in figure: 2 . $\beta$-carotene extraction was increased from $30^{\circ} \mathrm{C}$ to $40^{\circ} \mathrm{C}$ and then it decreased at $50^{\circ} \mathrm{C}$. At $40^{\circ} \mathrm{C}$, the yield of $\beta$-carotene was $16.625 \mathrm{mg} / 100 \mathrm{~g}$.

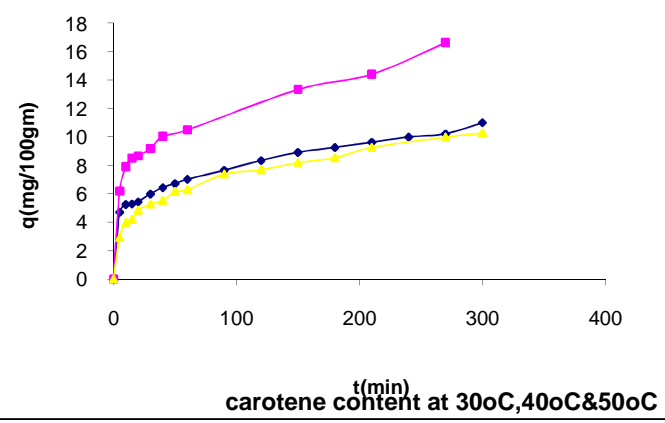

Fig-2: Amount of beta-carotene extracted from carrot in ethanol at $30^{\circ} \mathrm{C}, 40^{\circ} \mathrm{C}$, and $50^{\circ} \mathrm{C}$ (solid/liquid ratio: $1 / 40$ )

At $40^{\circ} \mathrm{C}$, the extraction yield of carotenes was found to be high after 10 min of extraction, which can be explained by a good release of carotenes from the disturbed texture of the carrot at $40^{\circ} \mathrm{C}$.At $40^{\circ} \mathrm{C}$, the extraction maximum was found after the fourth hour of extraction. After this time, the extraction yield of $\beta$-carotene decreased. The extraction was almost the same as the result of the degradation and loss of carotenes. Naturally, $\beta$-carotene exists in the all-trans form. After processing, some part of all-trans form is converted into its different cis-isomers [24]. Calvo et al. (2007) state, that in the extractions performed with ethanol at $50^{\circ} \mathrm{C}$, the yield of lycopene and its isomers was lower than $50^{\circ} \mathrm{C}$, that could indicate an extensive isomerisation at the high temperature with ethanol, but the oxidative degradation being the predominant reaction [23].

Optimal time for the best extraction of carotenes seems to be 4 to $5 \mathrm{~h}$, depending on the treatment of the sample; at lower temperatures $\left(40^{\circ} \mathrm{C}\right)$ and with fresh samples, a longer time (minimum $5 \mathrm{~h}$ ) is needed for the extraction Calvo et al. (2007) [23]. Rafajlovska et al. (2007) showed that the increase of temperature positively influences the mass transfer processes [25]. The increased color yields also result from the changes in the cellular structure of the biological matrix. On the other hand, the increase of the extraction temperature may cause raw material browning. Due to this circumstance, it is required to establish the optimal extraction temperature.
The processing of foods involves changes in the structural integrity of the matrix which produces both negative (loss of carotenoids due to oxidation) and positive (increased bioavailability) effects [26]. Light, heat etc. promote isomerisation of carotenoids. Oxidative degradation, the principal cause of extensive losses of carotenoids, depends on the availability of oxygen and is stimulated by factors such as light.

\subsection{Kinetic Models Study}

The calculated parameters for the empirical model with two exponential equations are presented in table: 2.The correlation coefficient is high in all experiments (0.91-0.99)(except Peleg model) yield for $\beta$-carotene extraction versus calculated extraction yield using the Power law, Pseudo second order and Intraparticle diffusion model at different extraction temperatures. It can be observed that a good agreement exit between experimental and calculated data.

The calculated parameters for the power law model (eq. 4) are presented in table: 2 . The correlation coefficient is also high in all the experiments (0.97-0.99), which implies that this model also fit also well with the experimental data. The figure: 3 corroborate also this conclusion. The calculated parameters for the Peleg model (eq. 5) are presented in table 2. For the Peleg model, the correlation coefficient is not high in all experiments (0.668-896) which that there is not good agreement between experimental and calculated data. The calculated parameters for the Weibull's equation (eq. 6) are presented in table: 2. For the Weibull's equation, the correlation coefficient is not so high in all experiments (0.91$0.95)$.

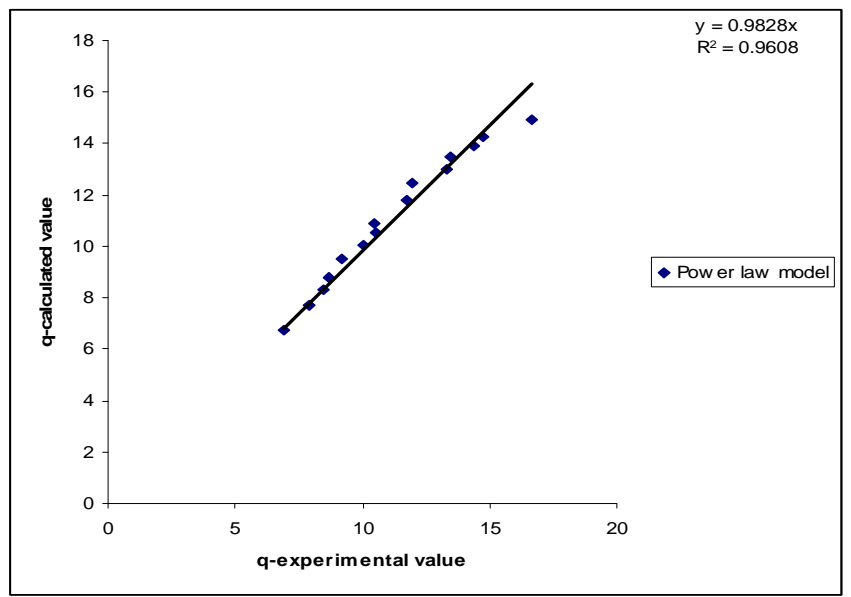

Fig- 3: Correlation between experimental values of extraction yield for beta-carotene extraction versus calculated extraction yield using power low model at $40^{\circ} \mathrm{C}$. 


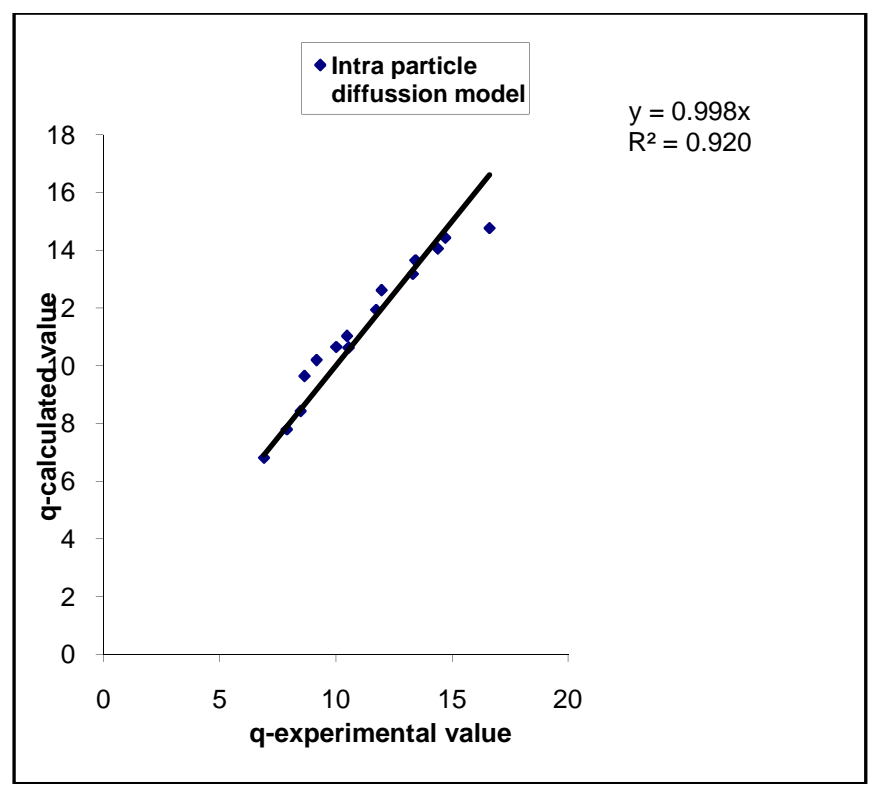

Table- 1 The amount of $\beta$-carotene extracted from carrot in different solvents (temperature: $30^{\circ} \mathrm{C}$, solid/liquid ratio: $1 / 5$ and extraction time: $5 \mathrm{hrs}$ )

\begin{tabular}{|c|c|c|c|}
\hline \multicolumn{3}{|c|}{ qeq values of particle with equivalent diameter $(\mathrm{cm})$} \\
$(\mathrm{mg} / 100 \mathrm{~g})$
\end{tabular}

Fig- 4: Correlation between experimental values of extraction yield for $\beta$ - carotene extraction versus calculated extraction yield using intra particle diffusion model at $40^{\circ} \mathrm{C}$.

Table- 2 Different model equation, model parameter for different empirical model at $30^{\circ} \mathrm{C}, 40^{\circ} \mathrm{C}$ and $50^{\circ} \mathrm{C}$

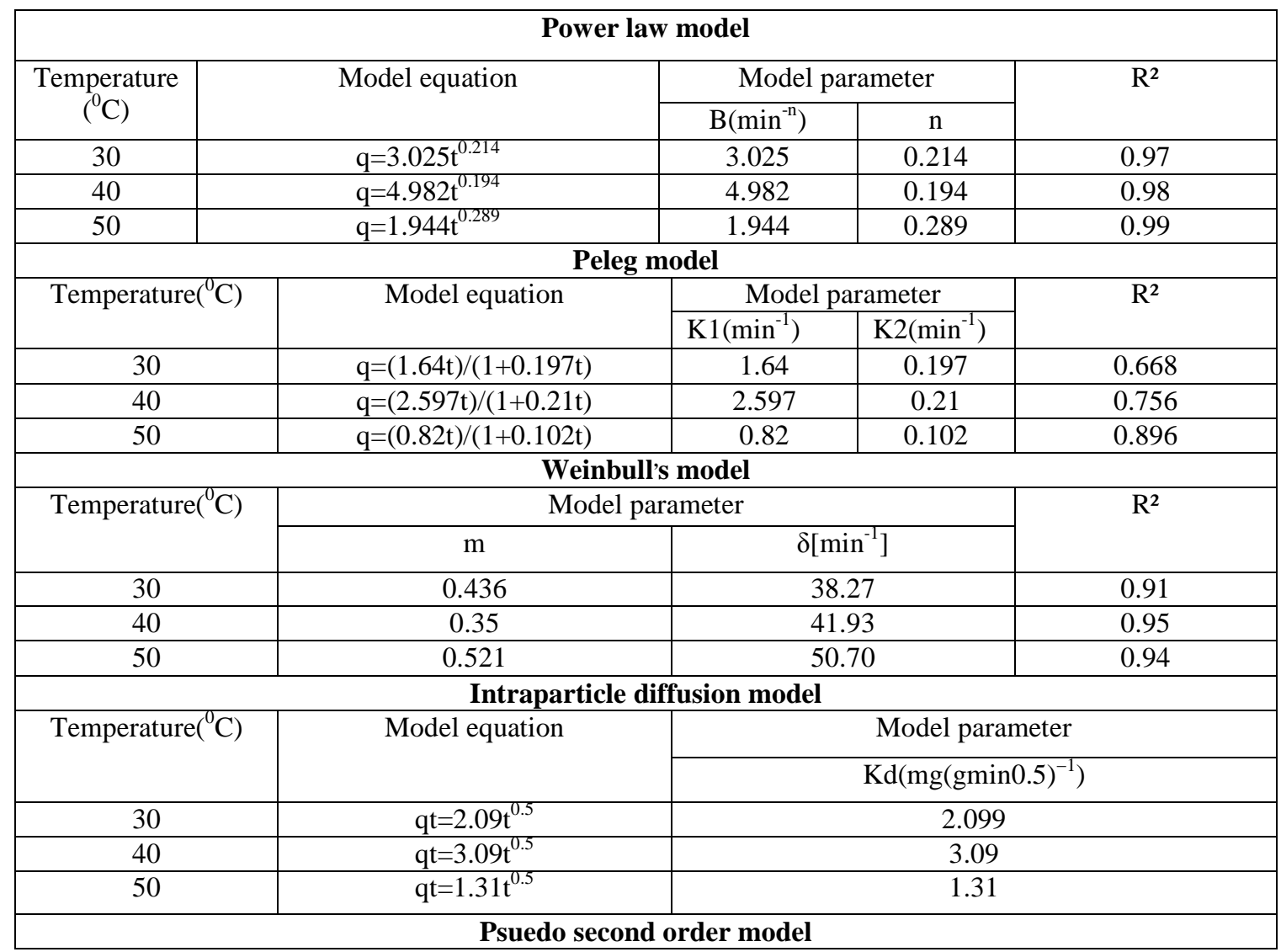




\begin{tabular}{|c|c|c|c|c|}
\hline Temperature $\left({ }^{0} \mathrm{C}\right)$ & Model equation & $\mathrm{qe}$ & $\mathrm{K} 2$ & $\mathrm{R}^{2}$ \\
\hline 30 & & & & \\
\hline 40 & $1 /(10.64-\mathrm{qt})=0.094+\left(4.29 \times 10^{-3} \mathrm{t}\right)$ & 10.64 & $4.29 \times 10^{-3}$ & 0.99 \\
\hline 50 & $1 /(15.38-\mathrm{qt})=0.065+\left(3.49 \times 10^{-3} \mathrm{t}\right)$ & 15.38 & $3.49 \times 10^{-3}$ & 0.99 \\
\hline
\end{tabular}

Table- 3: The color difference between original sample and sample extracted at $30^{\circ} \mathrm{C} \cdot 40^{\circ} \mathrm{C} \& 50^{\circ} \mathrm{C}$

\begin{tabular}{|c|c|c|c|c|c|}
\hline Raw/Extracted & $\mathrm{L}$ & $\mathrm{a}$ & $\mathrm{b}$ & $\Delta \mathrm{E}$ & $\mathrm{C}$ \\
& & & & & \\
\hline Original & 55.18 & 23.9 & 23.04 & & 33.44 \\
\hline $30^{\circ} \mathrm{C}$ & 34.08 & 9.91 & 12.49 & \pm 24.34 & 15.94 \\
\hline $40^{\circ} \mathrm{C}$ & 47.49 & 6.4 & 10.5 & \pm 28.58 & 12.30 \\
\hline $50^{\circ} \mathrm{C}$ & 50.12 & 10.91 & 14.49 & \pm 22.04 & 18.14 \\
\hline
\end{tabular}

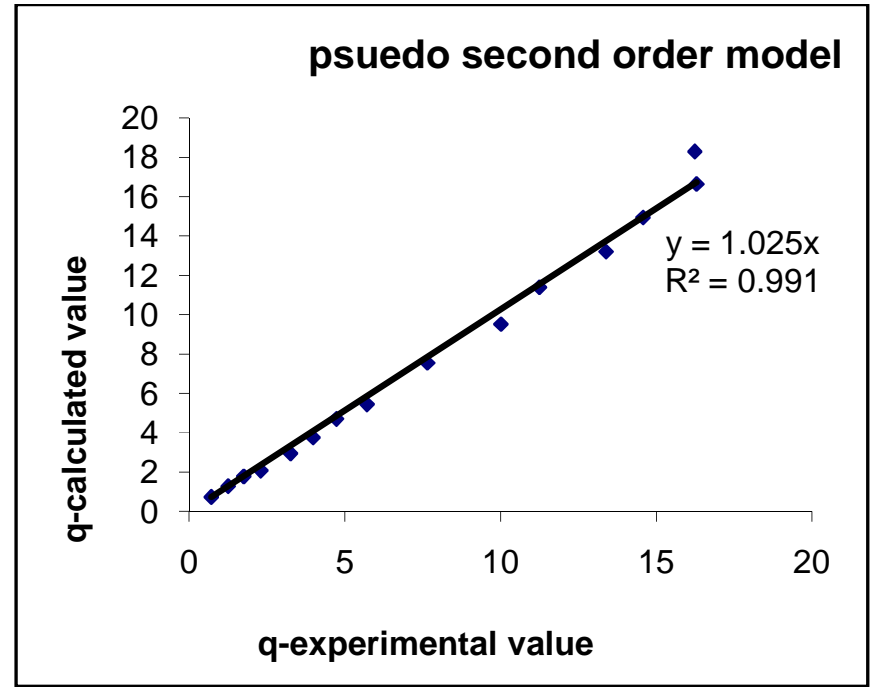

Fig- 5 Correlation between experimental values versus calculated values of pseudo second order model at $40^{\circ} \mathrm{C}$ (solid/liquid ratio: 1/40)

Figure: 3-5 shows the correlation between experimental values of extraction yield of $\beta$-carotene versus calculated extraction yield of different models. A good agreement between experimental and calculated data can be observed. The calculated parameters for the Intra particle diffusion and Pseudo second order are presented in table: 2.

\subsection{Hunter Lab Colorimeter Studies}

The colour was measured by Hunter Lab colorimeter. The colour difference $(\Delta \mathrm{E})$ between raw carrot and carrot after solvent extraction indicates the extent of $\beta$-carotene extraction. Table 3 indicates that the $\Delta \mathrm{E}$ value is maximum at $40^{\circ} \mathrm{C}$ and lowest extraction occurred at $50^{\circ} \mathrm{C}$.

\section{CONCLUSIONS}

An experimental study of $\beta$-carotene batch extraction from carrot under different experimental conditions was performed. The influence of different extraction conditions was also studied. The best solvent for $\beta$-carotene extraction was ethanol. The extraction yield increases with the increase of the solvent/solid ratio and with temperature. The empirical models tested showed a good agreement between experimental and calculated data, for all the models with high linear correlation coefficient $\left(R^{2}>0.91\right)$ except Peleg.

We can conclude that the temperature, increased up to $40^{\circ} \mathrm{C}$, positively influences the extraction yield of carotenes from carrot, however, for the technology of carrot processing we recommend to use lower temperatures of approximately 30 $40^{\circ} \mathrm{C}$. Ethanol is a more suitable solvent in terms of the carotenes yield as compared to other solvents. The described model technology for obtaining carotenoids can be modified (temperature of extraction, more-stages extraction). Besides carotenoids concentrate, another interesting by-product gained is dietary fiber, with excellent water binding capacity, which can be therefore used for functional foods production (as bread or pastry supplement).
ABBREVIATIONS
B - Parameter of power low model $\left[\mathrm{min}^{-\mathrm{n}}\right]$
$\mathrm{K} 1$ - parameter of the hyperbolic model; extraction rate at the very beginning $\left[\mathrm{min}^{-1}\right]$;
$\mathrm{K} 2$ - parameter of the hyperbolic model; constant related to the maximum extraction yield $\left[\mathrm{min}^{-1}\right]$;
$\mathrm{n}$ - Diffusional exponent of the power law model;
$\mathrm{m}$ - Shape parameter of the Weinbull's equation
q - Extraction yield (qt / qe)
$\mathrm{t}$ - Time [min]
qt- Amount of extracted carotene at any time. 
qe- Amount of carotene when equilibrium reached.

$\delta$ - Scale parameter of the Weinbull's equation $\left[\mathrm{min}^{-1}\right]$

$\mathrm{R}^{2}$-Coefficient of determination

qeq- Equivalent diameter of carrot cubes.

$\mathrm{K}_{\mathrm{d}}$-The intra-particle rate constant $\left(\mathrm{mg}\left(\operatorname{gmin}^{0.5}\right)^{-1}\right)$

\section{ACKNOWLEDGEMENTS}

Authors gratefully acknowledge TIFAC-CORE for financial support \& Techno India for infrastructural facilities.

\section{REFERENCES}

[1] Ferrari, C.K.B., 2004. Functional foods, herbs and nutraceuticals: Towards biochemical mechanisms of healthy aging. Biogerontology. 5, 275-289.

[2] Kanatt, S.R., Chander, R., Sharma, A., 2008. Chitosan and mint mixture: A new preservative for meat and meat products. Food Chem. 107, 845-852.

[3] Borowska, J., Kowalska, M., Czaplicki S., Zadernowski, R., 2003.Effect of hydrothermal processing on carrot carotenoids changes and interactions with dietary fiber. Nahrung, 47, 46-48.

[4] Schüep,W.,Schierle,J,1997.Determination of B-carotene in commercial foods: Interlaboratory study.J. AOAC Int., 80, 1057-1064.

[5] Sun, M., Temelli, F., 2006 Supercritical carbon dioxide extraction of carotenoids from carrot using canola oil as a continuous co-solvent. J. Supercrit. Fluids, 37, 397408.

[6] Ahlestten, H. Gotland,: 2008 Where History and Vision Meet to Create a New Model forDevelopment.SYSTEMAGINATION,p.3-

5.Availableonline: http://www.zeri.org/newsletters/ 200804Newsletter.pdf (accessed on 10 March 2009).

[7] Hulshof, P.J.M.,Xu, C.,van de Bovenkamp, 1997 P.Application of a validated method for the determination of provitamin A carotenoids in Indonesian foods of different maturity and origin. J. Agric. Food Chem.,45, 1174-1179.

[8] Gimeno, E., Castellote, A.I., Lamuela-Raventós, R.M., De la Torre, M.C., López-Sabater, M.C., 2002The effects of harvest and extraction methodson the antioxidant content (phenolics, alpha-tocopherol, and beta-carotene) in virgin olive oil. Food Chem.78, 207211.

[9] Fikselova, M., Silhar, S., Marecek, J., Francakova, H., 2008. Extraction of Carrot (Daucus carota L.) Carotenes under Different Conditions. Czech J. Food Sci., Vol. 26, No. 4: 268-274.

[10] de Quiros, A.R.B., Costa, H.S.,2006Analysis of carotenoids in vegetable and plasma samples: A review. J. Food Composit. Anal., 19, 97-111.

[11] Saldaña, M.D.A.,Sun, L,Guigard, S.E.,Temelli, F., 2006.Comparison of the solubility of [beta]-carotene in supercritical $\mathrm{CO} 2$ based on a binary and a multicomponent complex system. J. Supercrit. Fluids 37, 342-349.

[12] Hill, J., Nelson, E., Tilman, D., Polasky, S., Tiffany, D., 2006 Environmental, economic, and energetic costs and benefits of biodiesel and ethanol biofuels. Proc. Natl. Acad. Sci. USA, 103, 11206-11210.

[13] Kim, S., Dale, B.E., 2005.Environmental aspects of ethanol derived from no-tilled corn grain:Nonrenewable energy consumption and greenhouse gas emissions. Biomass Bioenerg., 28, 475-489.

[14] (Schoefs, 2004

[15] Nsonzi, F., \& Ramaswamy, H. S. (1998). Quality evaluation of osmoconvective dried blueberries. Drying Technology, 16(3e5), 705e723.

[16] Kitanoviae A, S., Millenoviae D., Veljkoviae A, V. B., 2008, Biochem. Eng. J., 41, p. 1

[17] Pelag, E., J. Food Sci., 53, 1988, p. 1216

[18] Mattea , F., Marttin , Á., Cocero , M. J., 2009. J. Food Eng., 93,p 255

[19] Jokiae ,S., Vellae , D., Billae , M., Buciae - Kojiae , A., Planiniae,M., Tomas , S., 2010.Czech J. Food Sci., 28, p. 206.

[20] Aksu.Z, 2001. Equlibriam and kinetic modeling of Cadmium biosorption by C.vulgaris in batch system: effect of temperature.Sep.Purif.Technol,285-294.

[21] Slovak Technical standard 56 0053. (1986): Determination of carotenes (A provitamins). UNN, Praha: 5.

[22] Belitz, H.D., Grosch, W., Schieberle, P., 2004. : Food Chemistry. Springer Verlag, Berlin: 1070.

[23] Calvo, M.M., Dado, D., Santa-Maria, G., 2007. Influence of extraction with ethanol or ethyl acetate on the yield of lycopene, $\beta$-carotene, phytoene and phytofluene from tomato peel powder. Euro Food Res and Technol, 224, 567-571

[24] Aman, A., Schieber, A.R., Carle, A., 2005. Effects of heating and illumination on trans-cis isomerization and degradation of $\beta$-carotene and lutein in isolated spinach chloroplasts. J.Agri Food Chem, 53, 9512-9518.

[25] Rafajlovska, V., Slaveska-Raicki, R., Koleva-Gudeva, L., Klopceska, J., 2007. Spice paprika oleoresin extraction under different conditions involving acetone and ethanol. Journal of Food, Agriculture \& Environment, 5, 65-69.

[26] Livny, O., Reifen, R., Levy, I., Madar, Z., Faulks, R., Southon, S., Schwartz, B., 2003: $\beta$-carotene bioavailability from differently processed carrot meals in human ileostomy volunteers. European Journal of Nutrition, 42, 338-345. 